\title{
A ruptura epistemológica entre psicanálise e ciências humanas na modernidade biológica
}

The epistemological rupture between psychoanalysis and human sciences at the biological modernity

La ruptura epistemológica entre el psicoanálisis y las ciencias humanas en la modernidad biológica

Cláudia Henschel de Lima*

\section{Resumo}

O artigo propõe abordar os fundamentos epistemológicos das ciências humanas com base no axioma, enunciado por Jacques Lacan, de que o sujeito da psicanálise é o sujeito da ciência e das contribuições críticas à Psicologia, de autores como Robert Blanché, Georges Canguilhem, Jean-Claude Milner e Michel Foucault. O artigo privilegiará as condições de surgimento da Psicologia e da orientação clínica na abordagem da experiência subjetiva, ao identificar que, para sustentar seu lugar no quadro do pensamento científico, a Psicologia converteu a problemática ética sobre as relaçóes entre o pensamento e a experiência subjetiva em um problema de determinação de leis explicativas sobre o funcionamento psíquico, adotando o postulado do realismo psicológico, em conformidade com uma modernidade biológica em ascensão. O texto expõe o modo como a psicanálise afirma pela subversão do sujeito, uma orientação ética em ruptura com um projeto cientificista que custou à Psicologia o preço de sua supressão.

Palavras-chave: psicanálise; sujeito; Psicologia; realismo psicológico.

\begin{abstract}
This article critically examines the epistemological foundations of psychology adopting the perspective of Robert Blanché, Georges Canguilhem, Jean-Claude Milner, Michel Foucault, and the Lacanian axiom (the subject of psychoanalysis is the subject of science) as well. It will emphasize the conditions of emergence of
\end{abstract}

\footnotetext{
Pós-doutoranda pelo programa de Pós-graduação em Psicanálise da UERJ, doutora em Psicologia Social e da Personalidade pela Universidade Federal do Rio de Janeiro (UFRJ), mestra em Teoria Psicanalítica pela Universidade Federal do Rio de Janeiro (UFRJ), professora adjunta do Departamento de Psicologia da Universidade Federal Fluminense - Escola de Ciências Humanas e Sociais - Polo Universitário de Volta Redonda. Endereço: Avenida Edison Passos, 603, apt.301. Alto da Boa Vista. CEP: 20531-073. Rio de Janeiro-RJ. Tel.: (21) 9214-9727 e (24) 3076-8803. Endereço eletrônico: claudiahlima@yahoo.com.br. Apoio técnico recebido no desenvolvimento do trabalho: Universidade Federal Fluminense - Escola de Ciências Humanas e Sociais - Volta Redonda-RJ.
} 
psychology and the clinical orientation in the approach of the subjective experience. It argues that psychology has taken the postulate of psychological realism, in line with a modern biological stream, in order to sustain its scientific status. As a consequence, psychology transformed the relationship between thought and subjective experience, an ethical issue, into a psychological functioning law puzzle, at the cost of suppressing the subject itself. In this sense, psychoanalysis is, as it highlights the meaning of the subversion of the subject, a rupture with the Psychology scientific project.

Keywords: psychoanalysis; subject; Psychology; psychological realism.

\section{Resumen}

El artículo examina críticamente la fundación epistemológica de la psicología adoptando la perspectiva de Robert Blanché, Georges Canguilhem, Jean-Claude Milner y Michel Foucault y el axioma de Lacan (el sujeto del psicoanálisis es el sujeto de la ciencia). El artículo priorizará las condiciones de fundación de la psicología y de la orientación clínica en el abordaje de la experiencia subjetiva. Sostiene que la psicología ha tomado el postulado del realismo psicológico, en la línea de la modernidad biológica para sostener su estado científico. Por consiguiente, la psicología transformó la relación ética entre el pensamiento y la experiencia subjetiva, en un problema epistemológico de determinación de las leyes del funcionamiento psicológico. En este sentido, el psicoanálisis destaca por la subversión del sujeto, la ocurrencia de una orientación ética en ruptura con el proyecto científico de la psicología.

Palabras clave: psicoanálisis; sujeto; Psicología; realismo psicológico.

\section{Consideraçõos iniciais}

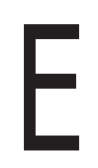

m A obra clara: Lacan, a Ciência, a Filosofia, Jean-Claude Milner (1996, p. 31-36) desenvolve uma reflexão sobre a relação entre psicanálise e ciência, tendo como eixo de argumentação os seguintes teoremas da ciência moderna extraídos da epistemologia de Alexandre Koyré:

1. Existe um corte entre a episteme antiga e a ciência moderna, que consiste na passagem do mundo do mais ou menos para o Universo da precisão. 
2. A ciência moderna é galileana, e seu projeto consiste em submeter o real à exigência de precisão e rigor do símbolo matemático.

3. O determinismo da ciência moderna estabelece a causa formal dos fenômenos sobre os quais se aplica: trata-se da elaboração de leis regulares para os fenômenos em ruptura com a concepção medieval do finalismo.

4. A ciência moderna é solidária à formulação de uma teoria do sujeito, destituído de qualidades empíricas, e fundamento desta.

Lacan estabelece uma releitura dos teoremas 2 e 3, nos seguintes termos: $2^{a}$ - A matematização do real tem limite; $3^{a}$ - O determinismo é incompleto.

No que se refere ao teorema 4, acerca do estatuto do sujeito da ciência, a releitura de Lacan denuncia a presença de uma divisão no saber científico. Se, por um lado, ao afirmar que não há ciência do homem, mas apenas seu sujeito, Lacan (1998, p. 873) aponta para o fato de o saber científico só dispor do símbolo matemático como medida do sujeito (conforme o teorema 2). Por outro lado, denuncia, na teoria cartesiana do sujeito (marco histórico do corte da ciência moderna), a presença de um fundamento metafísico garantidor da veracidade do saber científico (Lacan, 1985a, p. 39). Como, então, o saber científico se posiciona diante de sua própria divisão? Lacan (1998, p.875) responderá a essa pergunta afirmando que o saber científico se esforça em suturar a divisão do sujeito.

A partir dessa resposta, o sentido da subversão do sujeito em Lacan (1998, p. 853) é bastante preciso, exigindo a reflexão ética, sustentada pelo limite da literalização matemática do real e que fora suprimida pelo saber científico. A despeito do eixo da subversão do sujeito ter sido enunciado no quadro do primeiro ensino de Lacan, sustenta-se que seu sentido atravessa a totalidade de seus seminários e escritos, evidenciando a unidade da posição assumida pelo autor em relação ao saber científico: este sutura a divisão do sujeito. A pertinência da subversão do sujeito, no avesso da sutura, justifica-se pela presença, na contemporaneidade, de um revigoramento do determinismo neurofisiológico por meio do avanço do modelo biológico na explicação do psiquismo e da expansão tecnológica dos psicotrópicos na direção de tratamento das psicopatologias. Na verdade, o século XIX representa o marco histórico da solidarização entre a expansão do modelo biológico e o trabalho de constituição de uma ciência da razão pela Psicologia. De fato, ela definira o psiquismo como um aspecto do funcionamento orgânico e, mais particularmente, do sistema nervoso obedecendo, assim, a um duplo esforço de superação: 
1. Da distinção de natureza entre a alma e o corpo que possibilitava a investigação científica da realidade física, mas impossibilitava que o mesmo ocorresse com a alma.

2. Da organização dos saberes, derivada dessa distinção de natureza, e que separou, de um lado, a física-matemática (sustentada na submissão do real ao símbolo matemático) e, de outro, a metafísica (uma doutrina sobre o Cogito entendido como o fundamento de todo conhecimento possível).

No quadro da epistémè biológica que se abriu a partir do século XIX, Freud sustentou a hipótese do inconsciente e do recalcamento para explicar a causalidade dos sintomas neuróticos no avesso do vetor das ciências humanas que, por meio da Psicologia e de uma metodologia clínica em ascensão na psiquiatria, deixou-se submeter ao modelo biológico por acreditar que só assim era possível fundar uma ciência da razão.

Este artigo propõe abordar criticamente os fundamentos epistemológicos das ciências humanas desde o axioma, enunciado por Jacques Lacan (1998, p. 873), de que o sujeito sobre o qual a psicanálise opera é o da ciência. Recorrerse-á à análise epistemológica de autores que se posicionaram criticamente com relação à incidência do modelo biológico na explicação do psiquismo e na organização da metodologia clínica - Robert Blanché (1935), Georges Canguilhem (1966), Jean-Claude Milner (1968) e Michel Foucault (1985).

A primeira parte do artigo pretende apresentar os vetores epistemológicos que concorreram para o surgimento da Psicologia, no final do século XIX, e que implicaram a redução da problemática ética sobre as relações entre o pensamento e a vontade, entre o pensamento e o sujeito, a um problema epistemológico relativo à cientificidade dessa disciplina. A segunda parte pretende, pela análise crítica feita por Lacan, sobre a ascensão do modelo biológico na Psiquiatria e na Psicologia, abordar o impacto da redução da reflexão ética no domínio de investigação da experiência subjetiva.

\section{As condiçóes epistemológicas para a constituição da Psicologia}

A expansão de um modelo explicativo sobre o funcionamento mental na história da Psicologia e a integração do método experimental à metodologia de pesquisa tem seu marco no século XIX, quando as primeiras pesquisas localizacionistas sobre as faculdades mentais e a investigação dos processos sensoriais em fisiologia ofereceram à Psicologia experimental o modelo de investigação da estrutura do funcionamento psíquico. Assim, recorrendo à pesquisa fisiológica e, em seguida, às noçôes biológicas de hereditariedade e 
adaptação, bem como ao método experimental, a Psicologia encontrou nas ciências da vida o modelo para uma investigação científica do fato mental e, nas ciências da natureza, o cumprimento das exigências positivistas de objetividade e quantificação.

No clássico La Notion du Fait Psychique, Robert Blanché (1935) analisou os fundamentos epistemológicos da Psicologia, por meio do avanço da psicofísica no início do século XX. O autor localizou, nessa "física do espírito" (Blanché, 1935, p. 44), a evidência de que o projeto de fundar uma ciência do fato mental era inseparável do postulado do realismo psicológico ao preço da redução da experiência psicológica às sensações e da formulação de que o psiquismo é uma realidade que funciona de acordo com suas leis. Esse postulado foi criticamente elaborado por Blanché (1935) para:

1. Designar a relação de analogia entre a investigação científica do fato físico, conduzida pelas ciências da natureza, e a investigação do psiquismo, estando na base da adoção pela Psicologia dos estudos que correlacionam fato mental e atividade cerebral, e da pesquisa sobre a hereditariedade da conduta, que confere base física ao estudo da mente.

2. Diagnosticar o erro epistemológico cometido pela Psicologia que, em nome do projeto positivista de constituição de uma ciência da razão, considerou o psiquismo como uma realidade e equacionável à realidade física.

Esse posicionamento crítico com relação à Psicologia encontrou eco em outras referências clássicas no âmbito da reflexão epistemológica sobre a Psicologia. O mesmo erro epistemológico, diagnosticado por Blanché (1935), é apontado por Milner (1968, p. 225), ao denunciar que a Psicologia experimental se desenvolve em um mundo onde a verdade só pode falar do lado das coisas. Na mesma época, Canguilhem (1966, p. 77-86) esclarece que a Psicologia se constitui, no século XIX, como disciplina do comportamento humano, com o objetivo de determinar quantitativamente a capacidade técnica do indivíduo - em um contexto de época em que se articulam, de um lado, o modelo biológico organizado na forma de uma teoria geral das relações entre organismo vivo e meio e, de outro, uma ideologia dos valores da sociedade industrial direcionada para a abordagem instrumental das habilidades humanas. Da mesma forma, Lacan (1998, p. 77-95) analisa criticamente a constituição da Psicologia e acaba por isolar seu erro epistemológico no ponto em que converte o psiquismo em um fato, localizando nas entranhas do funcionamento 
cerebral sua causalidade empírica e o segredo de seu déficit: “[...] Devem explicar-se por algum determinismo estranho à sua 'aparência' e chamado de 'orgânico', por reduzi-los quer ao suporte de um objeto físico, quer à relação de um fim biológico" (Lacan, 1998, p. 82).

O conjunto dessas considerações certifica a ocorrência de uma consolidação do modelo biológico, na Psicologia, e sua aplicação na pesquisa sobre o psiquismo, exprimindo a sutura do saber científico como requisito indispensável para a consolidação de seu projeto epistemológico de constituir uma ciência da razão no final do século XIX. Uma consideração contemporânea, feita por John Searle (1998), a respeito da natureza da pesquisa contemporânea sobre o cérebro e a mente, evidencia a consolidação desse modelo e a perpetuação do clássico realismo psicológico como postulado da pesquisa psicológica experimental contemporânea:

Este dualismo entre a mente consciente e a matéria [...] foi útil para a pesquisa científica da época [...]. Mas tal dualismo se tornou um obstáculo para o século XX, já que parecia situar a consciência e outros fenômenos mentais fora do mundo físico ordinário e, por conseguinte, fora do domínio da ciência natural. No meu ponto de vista, temos de abandonar o dualismo e começar do pressuposto de que a consciência é um fenômeno biológico trivial, comparável ao crescimento, à digestão ou à secreção da bílis (Searle, 1988, p. 34).

O avanço do discurso científico no século XIX, sobre a consideração do homem moderno como ser vivo submetido a leis biológicas explicou, portanto, a constituição de uma Psicologia científica pautada no erro epistemológico que converteu o psiquismo em fato e, consequentemente, a própria temática ética da experiência subjetiva em um problema científico de determinação de leis explicativas sobre o funcionamento psíquico. No entanto, há ainda outro aspecto a ser abordado e de igual relevância para a análise da epistémè, que se configura na passagem do século XIX para o século XX e cujo produto final é o homem moderno: a relação entre o modelo biológico e as estratégias políticas, entre a transformação da vida em objeto do saber e os procedimentos de mensuração que são típicos das estratégias de poder. É Michel Foucault (1985) quem formaliza essa relação e denomina modernidade biológica a epistémè que se configura sobre ela:

Se pudéssemos chamar bio-história às pressões por meio das quais os movimentos da vida e os processos da história interferem entre si, deveríamos falar de biopolítica para designar o que faz com que a vida e seus mecanismos entrem no domínio dos 
cálculos explícitos [...]. Mas o que se poderia chamar de limiar de modernidade biológica de uma sociedade se situa no momento em que a espécie entra como algo em jogo em suas próprias estratégias políticas. $\mathrm{O}$ homem, durante milênios, permaneceu o que era para Aristóteles: um animal vivo e, além disso, capaz de existência política; o homem moderno é um animal, em cuja política, sua vida de ser vivo está em questão (Foucault, 1985, p. 134).

Assim, em relação ao final do século XIX, a análise biopolítica conduzida por Michel Foucault (1985) revela um diagnóstico similar ao de Canguilhem (1966, p. 79), ao sustentar que a formação do saber biológico é inseparável da biopolítica, ou seja, da intervenção crescente do Estado na disciplinarização dos corpos, por meio do procedimento de medida e avaliação do comportamento. É nesse quadro, de conjunção entre saber e poder, que a medicina e as ciências humanas se apresentam como disciplinas científicas sobre o normal e o patológico. No caso específico da Psicologia, esta é localizada (junto com a demografia, a estatística, a criminologia e a higiene social) no âmbito inicial das instituições disciplinares (hospitais, prisões, administrações), evidenciando a inseparabilidade entre a constituição das ciências humanas e as tecnologias de saber-poder investidas nessas instituições. Outro exemplo dessa inseparabilidade advém do saber médico que, no século XIX, elaborara uma teoria orgânica da doença para explicar a causalidade de um conjunto de condutas socialmente indesejáveis para a época: o alcoolismo, o sentimento de tristeza ou melancolia, a infância problemática e a violência (Caponi, 2007). Nesse contexto, a elaboração de Pinel sobre hipótese da herança como causa da loucura e a transformação dessas condutas em objeto da intervenção higienista e da Medicina Legal (Caponi, 2007; Costa, 2007; Santiago, 2004) representaram não só a consolidação do modelo biológico e do postulado do realismo psicológico na explicação biológica das psicopatologias (para além da Psicologia experimental), mas sua inserção em estratégias biopolíticas.

Essa forma de entender a organização das ciências humanas e do saber médico em torno da biopolítica contraria a ideia ordinariamente admitida, de que os progressos tecnológicos da medicina e da Psicologia explicam o avanço no conhecimento, no tratamento e no controle das doenças orgânicas (como a lepra e a tuberculose) e das psicopatologias. Ao contrário, o aparecimento das ciências clínicas do sujeito, com sua vasta compilação de dados e dossiês que esgotam as características externas das doenças, é paralelo à expansão e sofisticação de técnicas disciplinares de observação e análise do corpo, de modo a torná-lo mais apto à manipulação e ao controle. 
No final do século XIX, momento de constituição do projeto epistemológico de erguer uma ciência psicológica da razão, essa objetivação produzida pela conjunção saber-poder se manifestou pela atividade de recenseamento das populaçóes de acordo com a raça e a classe social, com a finalidade de medicalização e, consequentemente, de evitar a deterioração racial supostamente causada por degenerados hereditários (o cuidado eugênico).

Daí é possível, então, pensar que a presença do postulado do realismo psicológico, diagnosticado por Blanché (1935), é inseparável da transformação do campo de investigação do psiquismo em objeto de estratégia política. E, nessa perspectiva, a afirmação de Searle (1998) é um exemplo do erro epistemológico de perpetuar o homem pelo determinismo biológico bem como da articulação entre ciências humanas e:

1. A adoção do determinismo biológico para a explicação do psiquismo.

2. A sutura da divisão do saber científico.

3. O cientificismo, que localiza no déficit do funcionamento biológico, a explicação sobre a causalidade do sintoma.

4. A exigência biopolítica de quantificação do psiquismo.

\section{O ensino de Lacan no avesso do modelo biológico}

Os anos 50 representaram um momento importante de reestruturação dos fundamentos da clínica psiquiátrica, com base na expansão da tecnologia de síntese de psicotrópicos, com a descoberta da clorpromazina e da imipramina. Eles se constituem como modelo da série dos antipsicóticos e antidepressivos em um período de época, entre as ediçôes do DSM-II e do DSM-III, em que ainda vigorava o fundamento psicodinâmico da clínica psicopatológica. Essa expansão tecnológica da medicação é solidária da ascensão do modelo biológico de regulação do comportamento na clínica psiquiátrica, da elaboração de uma taxonomia pluralizada das psicopatologias com base em um modelo geral de regulação bioquímica do comportamento, e da organização da direção de tratamento das psicopatologias em torno da medicalização do psiquismo.

A distinção feita por Lacan (1992), entre a estrutura do saber científico e o impacto da difusão desse saber no mundo, ganha relevância nesse contexto, denunciando a presença de uma divisão no ponto em que o saber científico insiste em suturá-la. Assim, com base na perspectiva da teoria dos discursos - e, mais especificamente, desde a análise da posição do sujeito no discurso universitário (Lacan, 2008, p. 431-440) - constata-se a seguinte 
divisão do sujeito da ciência: se, por um lado, ele tem o controle efetivo dos procedimentos imanentes à condução de sua pesquisa e detém um saber especializado; por outro, desconhece seus determinantes e os efeitos de sua produção.

Sua análise conduz a pensar que o apelo à neutralidade científica é um sintoma desse ponto de ignorância que habita o sujeito em função da sutura de sua divisão: onde se apela para a exterioridade entre sujeito da ciência e seu objeto é onde se ancora o não saber do cientista sobre os efeitos da ciência. Isso se aplica à interrogação sobre o vivo conduzida pela medicina. Submetida ao modelo biológico, ela padece desse ponto de ignorância que, ao contaminar o médico, produz nele o desconhecimento quanto às consequências do avanço do saber biológico sobre sua conduta ética.

Essa consideração sobre a medicina remonta à passagem de Formulações sobre a Causalidade Psíquica (1998, p. 163-179), em que Lacan analisa a diretriz biológica de época para a compreensão da loucura. $\mathrm{O}$ autor se refere explicitamente ao modelo organicista para a investigação da loucura, elaborado por Henry Ey. Seu argumento é que tal diretriz compromete a especificidade da pesquisa sobre a loucura (objeto da prática psiquiátrica), conforme se afasta de uma orientação epistemológica pautada na definição racional do objeto de pesquisa. De fato, ao mostrar como o organodinamismo localizou, em uma escala comum, os transtornos psiquiátricos e os transtornos neurológicos, Lacan (1998) ironicamente levanta a hipótese de que resta à conduta ética na psiquiatria manter a diferença, entre ambos os transtornos, no plano meramente arquitetônico (ou o asilo ou o hospital):

Para falar em termos concretos, haverá alguma coisa que distinga o alienado dos outros doentes, a não ser pelo fato de o encerrarmos num asilo, enquanto hospitalizamos estes últimos? Ou ainda, será que a originalidade de nosso objeto é da prática - social - ou da razão científica?

Estava claro que Henry Ey só poderia afastar-se dessa razão, a partir do momento em que foi buscá-la nas concepções de Jackson. É que estas, por mais notáveis que fossem em sua época, por suas exigências totalitárias quanto ás funções de relação do organismo, têm por princípio e por fim levar a uma escala comum de dissoluções, distúrbios neurológicos e distúrbios psiquiátricos (Lacan, 1998, p. 155).

Essa ironia, que denuncia a ocorrência do mesmo erro epistemológico denunciado por Blanché (1935) a respeito da Psicologia, retorna no escrito $A$ Psiquiatria inglesa e a Guerra, no qual (Lacan, 2008, p. 124-125) verifica, na 
década de 1940, o impacto do modelo biológico no entendimento da experiência subjetiva, em uma referência direta à ascensão desse modelo e à expansão da tecnologia de psicotrópicos no contexto da II Guerra:

Minha exposição detém-se no ponto em que se descortinam os horizontes que nos projetam na vida pública, ou até, que horror!, na política. Sem dúvida, aí encontraremos objetos de interesse que nos compensarão por aqueles trabalhos apaixonantes do tipo "dosagem dos produtos de desintegração ureica na parafrenia fabulatória", inexauríveis produtos do esnobismo de uma ciência postiça, nos quais o sentimento predominante de inferioridade diante dos preconceitos da medicina, por parte de uma psiquiatria já ultrapassada era compensado (Lacan, 2008, p. 124).

A respeito dos saberes que se valem desse modelo para pensar o sujeito, ele os considera como falsa ciência a serviço de interesses biopolíticos e localiza, então, a redução da experiência subjetiva às substâncias secretadas pelo organismo como produto de uma psiquiatria biológica em ascensão e de uma Psicologia voltada para a avaliação e seleção.

Em O lugar da Psicanálise na Medicina (2001), Lacan dá continuidade a essa discussão, localizando uma crise ética na medicina, quando a posição do médico se converte na posição do especialista que detém um saber especializado sobre o corpo. Para isso, ele recorre aos achados da pesquisa arqueológica de Michel Foucault, em $O$ nascimento da clínica (1998), que remete tal crise ética ao surgimento, no século XIX, de uma medicina científica pautada na causalidade neurofisiológica do psiquismo e de seu déficit. Dessa forma, em observância ao saber científico, a medicina deixa de remeter a vida a um princípio metafísico e passa a relacioná-la à investigação empírica das células, tecidos, órgãos, sistemas e aparelhos que compõem um organismo. Lacan (2001) destaca dois momentos cruciais para o estabelecimento da medicina como ciência:

1. A promoção por Xavier Bichat do olhar direcionado para o corpo e objetivado na prática anatomopatológica.

2. A exigência da condição experimental por Claude Bernard.

Em concordância com a argumentação desenvolvida por Foucault (1998), Lacan (2001) isola as duas dimensôes da crise ética na medicina. De um lado, está profundamente marcada pelo acontecimento epistemológico de destituição do homem em relação a sua origem metafísica e por sua constituição, a partir do século XIX, em objeto que serve às exigências do discurso científico; de outro, sua prática clínica é marcada pela intervenção técnica do especialista, 
ao preço da dissolução de seu objeto de investigação. Seguindo a mesma linha da argumentação crítica de Blanché (1935), Canguilhem (1966) e Milner (1968) Lacan (1998, p. 214-216) já localizara o fundamento epistemológico das ciências humanas na reificação do homem por meio do determinismo biológico (como é o caso, por exemplo, da Psicologia), do esquecimento de sua determinação dialética e de sua redução a objeto da quantificação matemática.

Contemporaneamente, verifica-se a presença de uma teoria do inconsciente no domínio de investigação da ciência cognitiva dedicada à pesquisa da memória, alicerçada na metodologia experimental e no fundamento biológico. Esse domínio da ciência cognitiva deixa de lado o fato de Freud (1976b) definir o inconsciente em torno de uma falta originária, constitutiva, no avesso de uma memória armazenada, e de elaborar a teoria da pulsão de morte para formalizar o ponto de fuga do sentido imanente a ele: "Mas tudo tem de ser pago de uma maneira ou de outra, e esse sucesso é alcançado ao preço de uma fenda no eu, a qual nunca se cura, mas aumenta à medida que o tempo passa" (Freud, 1976b, p. 309).

A exclusão cognitivista da falta originária e da pulsão de morte evidencia a presença do postulado do realismo psicológico (Blanché, 1935) pela redução do inconsciente a uma função psicológica de armazenamento e processamento da informação, cujo correlato é localizável em áreas específicas da atividade neural. Mas evidencia, principalmente, a presença do viés biopolítico das ciências humanas na contemporaneidade, que recusa a especificidade da experiência subjetiva em nome:

1. Da exigência, no campo da Psicologia, de quantificação das habilidades instrumentais.

2. Da elaboração, no campo da psiquiatria, de um modelo explicativo das psicopatologias fundamentado na neurofisiologia e solidário da tecnologia de síntese de medicamentos.

Um caso clássico é a invalidação do diagnóstico diferencial neurose-psicose, com base na prescrição da imipramina para ambas as psicopatologias. De fato, a publicação, em 1962, do artigo de Donald Klein sobre os padrões de reação à imipramina demonstrou a futilidade, para a psiquiatria biológica, de uma pesquisa clínica em torno do diagnóstico diferencial. Sobre as implicaçôes de uma farmacologia, indissociável dos interesses de mercado, sobre a disciplina do diagnóstico diferencial, é possível concordar com Laurent (1995, p. 156): 
Certamente, uma das contribuições fundamentais da psicofarmacologia é ter podido mostrar a eficácia do tratamento antes reservado à psicose maníaco-depressiva clássica em outras patologias, tais como as esquizofrenias distímicas, bem como nos distúrbios do comportamento alimentar ou nas chamadas patologias neuróticas tão bem definidas, em termos semiológicos, quanto os distúrbios obsessivo-compulsivos.

Nesse quadro de uma psicofarmacologia orientada pelos interesses de mercado, a American Psychiatry Association (APA) extraiu, no final da década de 1970, o fundamento biológico para o DSM-III, em ruptura com o modelo psicanalítico, ainda predominante no DSM-II, até chegar ao extremo da investigação sobre a causalidade cromossomial da psicose para a quinta edição do DSM, a ser publicada em 2012.

É fato que Freud (1976a, p. 171-183) já se insurgira contra os analistas que idealizavam a publicação de seus êxitos terapêuticos temendo, com isso, associar a psicanálise às exigências biopolíticas de readaptar o sujeito ao ambiente da guerra. Sustentar a dimensão ética da experiência subjetiva fundamentada nos diferentes modos de enlaçamento entre a pulsão e as representaçôes inconscientes, ou entre o gozo e o significante, implica contrapor-se à modernidade biológica e a romper epistemologicamente com o empuxo biopolítico para a mensuração das habilidades humanas (Canguilhem, 1966), que motiva o erro epistemológico subjacente ao postulado do realismo psicológico. É nesse sentido que o axioma o sujeito sobre o qual a psicanálise opera é o sujeito da ciência (Lacan, 1998, p. 873) localiza a subversão do sujeito no ponto em que o sujeito da ciência é produto da sutura de sua divisão constitutiva, reivindicando para isso sua unidade pela insistência em correlacionar a experiência subjetiva a padrôes de atividade neural.

Para finalizar, dir-se-ia que a escandalosa atualidade do posicionamento ético de Freud e Lacan reside em não ter recuado diante do incomensurável de uma exigência que serve para nada (Lacan 1985b, p. 7). Sendo assim, o ensino de Lacan assumiu uma direção distinta da paixão da modernidade biológica pela determinação neurofisiológica do sujeito, desde o momento em que recorreu à lógica do significante (passando pela teoria do objeto $a$ ) até o momento mais radical, em que, em seu último ensino, defenderá um real próprio à psicanálise, incomensurável, resistente à literalização operada pelo saber científico e, portanto, irredutível a uma norma proposta pelo modelo biológico. 


\section{Referências}

Blanché, R. (1935). La Notion du Fait Psychique. Paris: Felix Alcan.

Canguilhem, G. (1966). Qu'est-ce que la Psychologie? Cahiers pour l'Analyse, 1(2), 77-86.

Caponi, S. (2007). Da herança à localização cerebral: sobre o determinismo biológico das condutas indesejadas. Physis: Revista de Saúde Coletiva, 17 (2), 343-352.

Costa, J. F. (2007). História da Psiquiatria no Brasil: um corte epistemológico. Rio de Janeiro: Garamond.

Foucault, M. (1985). História da sexualidade I: a vontade de saber. Rio de Janeiro: Ed.Graal.

Foucault, M. (1998). O nascimento da clínica. Rio de Janeiro: Forense Universitária.

Freud, S. (1976a). Uma dificuldade no caminho da psicanálise. In: Edição standard das obras psicológicas completas de Sigmund Freud. (Jayme Salomão, trad., Vol. 17, pp. 171-183). Rio de Janeiro: Imago. (Texto original publicado em 1917).

Freud, S. (1976b). A Divisão do Ego no Processo de Defesa. Edição standard das obras psicológicas completas de Sigmund Freud. (Jayme Salomão, trad., Vol. 23, p. 309-313). Rio de Janeiro: Imago. (Texto original publicado em $1940[1938])$.

Klein, D. (1962). Psychiatric Reaction Patterns to Imipramine. American Journal of Psychiatry, 119, p. 432-438.

Lacan, J. (1985a). O seminário: livro 11: os quatro conceitos fundamentais da psicanálise (1964). Rio de Janeiro: Jorge Zahar.

Lacan, J. (1985b). O seminário: livro 20: mais ainda (1972-1973). Rio de 
Janeiro: Jorge Zahar.

Lacan, J. (1992). O seminário: livro 17: o avesso da psicanálise (1969-1970). Rio de Janeiro: Jorge Zahar.

Lacan, J. (1998). Escritos. Rio de Janeiro: Jorge Zahar.

Lacan, J. (2001). O lugar da psicanálise na Medicina. Opção Lacaniana, 32, 8-14. (Texto original escrito em 1966).

Lacan, J. (2003). Outros escritos. Rio de Janeiro: Jorge Zahar.

Laurent, E. (1995). Melancolia, dor de existir, covardia moral. In: Laurent, E. Versōes da clínica psicanalítica. (pp. 155-166). Rio de Janeiro: Jorge Zahar.

Milner, J-C. Que é a Psicologia?. In: Prado Coelho, E. (1968). Estruturalismo: antologia de textos teóricos. (pp. 225-227). Portugal: Portugália. (Texto originalmente publicado em 1966)

Milner, J-C. (1996). A obra clara: Lacan, a ciência, a filosofia. Rio de Janeiro: Jorge Zahar.

Santiago, J. (2004). O significante contábil do neo-higienismo. Opçãa Lacaniana, 39, 3-8.

Searle, J. (1998). O mistério da consciência. São Paulo: Paz e Terra. 